\title{
Assessment of Lead and Arsenic Levels in Human Blood Through Exposure to Nail Polish
}

\author{
Renato I Dalmacio*1 ${ }^{* 1}$ and Susan S Montemayor ${ }^{2}$ \\ ${ }^{1}$ Graduate School, Centro Escolar University, Philippines \\ ${ }^{2}$ School of Pharmacy, Centro Escolar University, Philippines
}

Submission: November 11, 2017; Published: November 27, 2017

*Corresponding author: Renato I Dalmacio, Graduate School, Centro Escolar University, Philippines, Email: rhenato_mdpharma@yahoo.com

\begin{abstract}
Background: Nail polish that we used today may contain the following toxic chemicals like dibutylphthalate, toluene and formaldehyde as well as traces of heavy metals that may produce toxicity. The combination of chemicals used to help the colour bond and harden to fingernails often includes substances that are known neurotoxins, carcinogens, and hormone disrupters

Objective: The purpose of this study was to assess the lead and arsenic levels in human blood through exposure to nail polish and to correlate its results to the serious effects of lead and arsenic on human health.

Method: The study was carried on human blood samples extracted from 90 research subjects of three identified groups: non-nail polish users (NNPU), nail salon workers-non nail polish users (NSW-NNPU) and nail salon workers-nail polish users (NSW-NPU). The lead (Pb) and arsenic (As) content in human blood were analyzed using inductively coupled plasma-optical emission spectrometry (ICP-OES). The human blood samples were also subjected to complete blood count (CBC) to determine the correlation of hemoglobin level of the three groups of human respondents with the lead and arsenic content.
\end{abstract}

Results: Based on the results of the ICP-OES analysis, nail salon workers-non nail polish users were reported to have the highest mean blood concentration of $0.19190 \mathrm{ppm}(\mathrm{Pb})$ and $0.35403 \mathrm{ppm}(\mathrm{As})$ respectively. The data obtained was computed using Analysis of Variance (ANOVA). The results showed that there is a very significant difference between NNPU versus NSW-NNPU, NNPU versus NSW-NPU and NSW-NNPU versus NSW-NPU with a p-value of $<0.01$ for lead and arsenic content respectively. On the other hand, there is a very significant correlation between the hemoglobin levels of nail salon workers-non nail polish users with the lead and arsenic content with the $p$-value of $<0.01$ and $r$-values of -0.793 (Lead) and -0.822 (Arsenic).

Conclusion: The results revealed that high level concentrations of lead and arsenic found in the blood of nail salon workers-non nail polish users have direct impact to the hemoglobin level of the said group which can lead to anemia [1-2].

Keywords: Arsenic; Inductively Coupled Plasma-Optical Emission Spectrometry (ICP-OES); Lead; Nail Polish

Abbreviations: BOC: Bureau of Customs; FDR: Food and Drug Regulation; NNPU: Non-Nail Polish Users; NSW-NPU: Nail Salon Workers-Nail Polish Users; NSW-NNPU: Nail Salon Workers- Non Nail Polish Users; ICP-OES: Inductively Coupled Plasma-Optical Emission Spectrometry; PPE: Personal Protective Equipment; FDA: Food and Drug Administration

\section{Introduction}

One of the trending issues nowadays in the country is the problem regarding smuggled products coming from different countries that do not follow the regular process of Bureau of Customs (BOC). Most of these products are believed to be of substandard quality and do not reflect the actual integrity which may affect the health of the public. One good example of smuggled product sold by the vendors in the sidewalks and some of the establishments in the country is nail polish. Nail polish available in the market varies from different shades and colours and wide selections of brands that can be purchased by the respective consumer. The selling price of each nail polish ranges from as low as 15 pesos to the most expensive brand that cost more than 1000 pesos. However, because of the crippled economy and low income salary, most consumers are resorted to buy the unregistered brand of nail polish which is alarming to the government authority especially the Food and Drug Regulation (FDA). These unregistered brands of nail polish were illegally imported and sold in the Philippine market. Buying unregistered nail polish is dangerous to health since the active ingredient is unknown and may cause harm to consumers. The most common 
toxic chemicals are formaldehyde, toluene, dibutyl phthalate and heavy metals like arsenic and lead which are strongly prohibited to be present in nail polish [3-4].

\section{Statement of the Problem}

The purpose of this research study was to assess the lead and arsenic levels in human blood through exposure to nail polish. Specifically, this research study was intended to answer the following questions:

a) What is the concentration of lead and arsenic present in the blood of the following human respondents: non-nail polish users (NNPU), nail salon workers-nail polish users (NSW-NPU) and nail salon workers-non-nail polish users (NSW-NNPU)?

b) What is the hemoglobin count of the following human respondents: non-nail polish users (NNPU), nail salon workers-nail polish users (NSW-NPU) and nail salon workers-non-nail polish users (NSW-NNPU)?

c) What are the possible sources of lead and arsenic among the people that was asked in the survey questionnaire?

d) Is there a significant difference in the lead and arsenic content present in human blood between non-nail polish users (NNPU), nail salon workers-nail polish users (NSWNPU) and nail salon workers-non-nail polish users (NSWNNPU)?

e) Is there a correlation between the hemoglobin level of non-nail polish users, nail salon workers-non nail polish users and nail salon workers-nail polish users with the lead and arsenic concentration found in the blood of the human respondents?

f) Does the blood level of lead and arsenic conform to the standard limits set by World Health Organization?

\section{Methods and Procedures}

The descriptive method was applied by the researcher and a self-made survey questionnaire was used as the primary instrument in gathering data. The questionnaire was consisting of the demographic profile of the respondents and the possible sources of lead and arsenic. Informed consent was secured from the research subjects. Preliminary research and unstructured interviews were also conducted to further increase the understanding about the subject matter. The subjects of the study were composed of thirty (90) human respondents in three identified groups namely: non-nail polish users, nail salon workers-non nail polish users, nail polish users and nail salon workers-nail polish users. The experimental method was also performed to determine the lead and arsenic levels in human blood samples using Inductively Coupled Plasma-Optical Emission Spectrometry (ICP-OES) as the method of analysis. The lead $(\mathrm{Pb})$ content was determined at the wavelength of 220.353 nanometre, whereas arsenic (As) content was determined at
188.890 nanometre. To ensure impartiality on presentation, analysis and interpretation of data, the researcher used statistical tools such as: Mean, Standard Deviation Frequency and Percentage Distribution and T-test for independent variables [5].

\section{Summary of Findings}

Based on the results of the research study, the following findings were gathered by the researcher:

I. Nail Salon Workers-Non Nail Polish Users were reported to have the highest mean concentration of lead (0.1919 ppm) and arsenic (0.35403 ppm) in the human blood samples.

II. Nail Salon Workers-Non Nail Polish Users were reported to have the lowest hemoglobin count of $127.90 \mathrm{~g} / \mathrm{L}$ in the human blood samples followed by Nail Salon WorkersNail Polish Users with the hemoglobin count of 129.03 g/L.

III. The respondents have revealed that $78 \%$ of them were using cosmetic products aside from nail polish. It was also presented that $47 \%$ of them were using lipstick as their personal choice of cosmetics. In addition to cosmetic products, $70 \%$ of the respondents were eating imported canned goods. Also $60 \%$ of the respondents were smoking or considered second-hand smoke. Furthermore, small percentage of the respondents was reported to use the following in their house respectively: paints (20\%), gasoline (10\%) and pesticides (27\%).

IV. The data obtained from ICP-OES analysis was calculated using Analysis of Variance and the results showed that there is very significant difference in the lead and arsenic content present in the human blood between non-nail polish users versus nail salon workers-non nail polish users, non-nail polish users versus nail salon workers- nail polish users and nail salon workers-non nail polish users versus nail salon workers- nail polish users. The results showed a p-value of $<0.01$ for lead and arsenic respectively.

V. The data obtained from the complete blood count was used to compute for the correlation of hemoglobin level among the three groups of human respondents with the lead and arsenic content and it found out that Nail Salon WorkersNon Nail Polish Users have very significant correlation with reported $p$ value of $<0.01$ and $r$-values of- 0.793 (Lead) and -0.822 (Arsenic)

VI. The results of ICP-OES analysis showed that blood levels from Nail Salon Workers-Non Nail Polish Users have almost reached the standard limit of $0.2 \mathrm{ppm}$ for lead while Nail Salon Workers-Nail Polish Users and Non-Nail Polish Users are still on tolerable level. On the other hand, blood level from Nail Salon Workers-Non Nail Polish Users and Nail Salon Workers-Nail Polish Users has exceeded the standard limit of 0.05 ppm while Non-Nail Polish Users are considered 
very low level.

\section{Conclusion}

Based on the above findings, the researcher arrived with the following conclusions. Among the three groups of human subjects, nail salon workers-non nail polish users are considered to have the highest exposure with lead and arsenic. The result of ICP-OES analysis showed that high blood levels of lead and arsenic can be attributed to their use of chemicals and cosmetic products as part of their everyday job routine aside from nail polish. In addition to that, majority of the nail salon workers during the interview were not using personal protective equipment (PPE) like gloves, face mask and goggle. Meanwhile, the result of the complete blood count has revealed that nail salon workers-non nail polish users have the lowest hemoglobin level among the three groups of human respondents. Lastly, because of the mentioned factors above, it found out there is a very significant correlation with the hemoglobin levels with lead and arsenic content in the human blood samples of the nail salon workers-non nail polish. The results revealed that high level concentrations of lead and arsenic found in the blood of nail salon workers-non nail polish users have direct impact to the hemoglobin level of the said group which can lead to anemia [6-7].

Because of these results, nail salon workers-non nail polish users were advised to immediately consult a physician in order to address this matter. On the other hand, there is a very significant difference in the lead and arsenic content between non-nail polish users versus nail salon workers-non nail polish users, non-nail polish users versus nail salon workers- nail polish users and nail salon workers-non nail polish users versus nail salon workers- nail polish users which can be partly attributed to the use of cosmetic products aside from nail polish. Lastly, non-nail polish users are considered to be the least or minimal exposure with lead and arsenic. The result shows that non-nail polish users are aware of the harmful effects of these heavy metals that can be acquired from the use of different cosmetic products as well as exposure with industrial and agricultural products. It can be

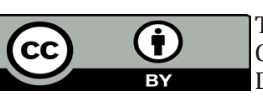

This work is licensed under Creative Commons Attribution 4.0 License DOI: 10.19080/JPCR.2017.04.555639 also implied that most of the products they used has conformed to the maximum allowable limit set and implemented by the Food and Drug Administration (FDA).

\section{Recommendations}

In the light of the findings and conclusion of the study, the researcher would like to recommend for the benefit of the population to further study the following:

A. Select a group of human respondents with predetermined target limit between age, gender and occupation.

B. Extend the site of sample collection involving the nail salons located in different barangay or streets.

C. Utilize different matrix of human samples such as nails and hair.

D. Utilize different form of cosmetic products known to have lead and arsenic content that human subjects may be exposed.

E. Determine the extent of exposure of the human respondents with lead and arsenic.

\section{References}

1. Casas JS, Sordo J (2011) Lead: Chemistry, Analytical Aspects, Environmental Impact and Health Effects. Elsevier, Europe.

2. Draelos ZD (2011) Cosmetic Dermatology: Products and Procedures. John Wiley \& Sons.

3. Epstein SS (2013) Toxic Beauty: How Cosmetics and Personal-Care Products Endanger Your Health... and What You Can Do About It. BenBella Books, Inc.

4. Luttrell WE, Jedenberg WW, Still KR (2008) Toxicology Principles for the Industrial Hygienist. AIHA.

5. Margill AJ, Strickland GT, Maguire JH, Ryan ET, Solomon T (2012) Hunter's Tropical Medicine and Emerging Infectious Disease: Expert Consult. Elsevier Health Sciences, Europe.

6. Melnick EL, Everitt BS (2008) Encyclopedia of Quantitative Risk Analysis and Assessment, Volume 1 John Wiley \& Sons, USA.

7. Ramachandran G (2005) Occupational Exposure Assessment for Air Contaminants. CRC Press, USA.

\section{Your next submission with Juniper Publishers will reach you the below assets}

- Quality Editorial service

- Swift Peer Review

- Reprints availability

- E-prints Service

- Manuscript Podcast for convenient understanding

- Global attainment for your research

- Manuscript accessibility in different formats

( Pdf, E-pub, Full Text, Audio)

- Unceasing customer service

Track the below URL for one-step submission https://juniperpublishers.com/online-submission.php 